\title{
Importance of basal boundary conditions in transient simulations: case study of a surging marine-terminating glacier on Austfonna, Svalbard
}

\author{
YONGMEI GONG, ${ }^{1,2}$ THOMAS ZWINGER, ${ }^{3}$ STEPHEN CORNFORD, ${ }^{4}$ \\ RUPERT GLADSTONE, ${ }^{2,5}$ MARTINA SCHÄFER, ${ }^{2,6}$ JOHN C. MOORE $^{2,7}$ \\ ${ }^{1}$ Division of Atmospheric Sciences, University of Helsinki, Helsinki, Finland \\ ${ }^{2}$ Arctic Center, University of Lapland, Rovaniemi, Finland \\ ${ }^{3}$ CSC-IT Center for Science, Espoo, Finland \\ ${ }^{4}$ Bristol Glaciology Center, University of Bristol, Bristol, UK \\ ${ }^{5}$ CRC-Antarctic Climate \& Ecosystems, University of Tasmania, Hobart Tasmania, Australia \\ ${ }^{6}$ Finnish Meteorological Institute, Helsinki, Finland \\ ${ }^{7}$ Joint Centre for Global Change Studies, College of Global Change and Earth System Science, Beijing Normal University, \\ Beijing, China \\ Correspondence: John C. Moore <john.moore.bnu@gmail.com>
}

\begin{abstract}
We assess the importance of basal boundary conditions for transient simulations of Basin 3, Austfonna ice cap between January 1995 and December 2011 and for the surge starting in 2012 by carrying out simulations with the full-Stokes model Elmer/Ice and the vertically-integrated model BISICLES. Time-varying surface mass-balance data from the regional climate model HIRHAM5 are downscaled according to elevation. Basal friction coefficient is varied through time by interpolating between two data-constrained inversions of surface velocity fields, from 1995 and 2011. Evolution of the basal boundary condition appears to be much more important for mass discharge and the dynamic response of the fast flowing unit in Basin 3 than either model choice or the downscaling method for the surface mass balance. In addition, temporally linear extrapolation of the evolution of basal friction coefficient beyond the 2011 distribution could not reproduce the expansion of the acceleration observed in southern Basin 3 between January 2012 and June 2013. This implies that changes in basal friction patterns, and in turn basal processes that are not currently represented in either model, are among the most important factors for the 2012 acceleration.
\end{abstract}

KEYWORDS: basal sliding, glacial modeling, transient simulation

\section{INTRODUCTION}

Large scale ice dynamic models (IDMs) are widely used to understand the behavior of ice caps and ice sheets and their response to climate change, particularly with regard to sea-level rise (Moore and others, 2013). The majority of IDMs are based on conservation laws for mass, linear momentum and internal energy, but their results depend on how approximations to these conservation laws are implemented in the models as well as on the treatment of traction at the ice/bed interface and the coupling of climate forcing to the IDM (e.g. Pattyn, 2003; Gagliardini and others, 2007; Pattyn and others, 2008; Gong and others, 2014; Schäfer and others, 2015). For large ice sheets and ice caps, the transient behavior is primarily determined by surface mass balance (SMB) and ice dynamics (e.g. Edwards and others, 2014).

Austfonna, located on the island of Nordaustlandet, Northeastern Svalbard, is at $7800 \mathrm{~km}^{2}$ the largest ice mass in the Eurasian Arctic in terms of area, (Moholdt and Kääb, 2012) and rises to $\sim 800 \mathrm{~m}$ a.s. (Fig. 1). The ice cap has two distinct types of drainage basins (Dowdeswell and others, 1986): the northwestern basins are drained for the most part through land-terminating outlets or outlets that terminate in narrow fjords; the southeastern basins consist mostly of marine-terminating outlet glaciers that are grounded below sea level at their termini. The Barents Sea, to the southeast of the ice cap, provides most moisture to the ice cap, which has a distinct southeast to northwest accumulation gradient (Schytt, 1964; Pinglot and others, 2001; Taurisano and others, 2007; Dunse and others, 2009). The interior of the ice cap has been thickening since at least 1996 (Bamber and others, 2004; Moholdt and others, 2010).

Many of the Austfonna outlet glaciers are known to undergo periodic surges, during which mass loss is significantly amplified for several years (Dowdeswell and others, 1986). Recently the outlet glacier in one of its basins, Basin 3 , began to surge, contributing an estimated $7.2 \pm 2.6 \mathrm{Gt}$ $\mathrm{a}^{-1}$ to sea-level rise, which is as large as the total mass lost $\left(6.6 \pm 2.6 \mathrm{Gt} \mathrm{a}^{-1}\right)$ from the entire archipelago over the whole 2003-08 period (Dunse and others, 2015).

Basin 3 is located in southeastern Austfonna and is grounded as much as $150 \mathrm{~m}$ below sea level at its terminus (Dowdeswell and others, 1986; Dunse and others, 2011). The fast flowing region of Basin 3 is constrained by subglacial mountains to its north and was observed to have surged in 1873 (Lefauconnier and Hagen, 1991). Resent observations show that the outlet glacier in Basin 3 entered its active surge phase again in autumn 2012 following an acceleration phase which started in the early 1990s (Dowdeswell and others, 1999) and activated a former slow flowing area in the 

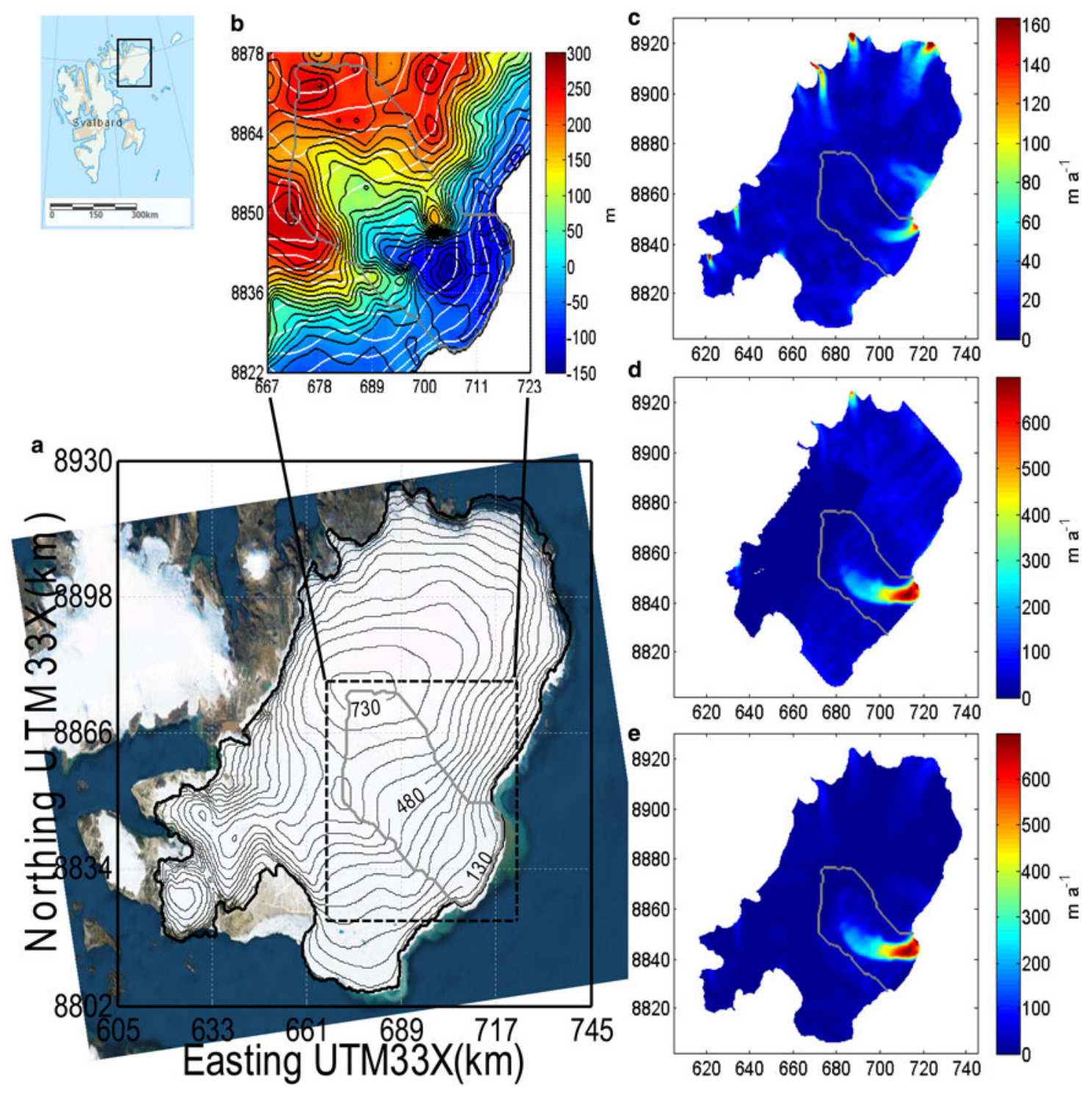

Fig. 1. Topography data and surface flow speed. (a) Surface elevation contours at $50 \mathrm{~m}$ intervals with solid black lines. (b) Bedrock topography contours are at $20 \mathrm{~m}$ intervals with solid black lines and superimposed with $50 \mathrm{~m}$ surface elevation contours in white. Observed winter surface flow speed from (c) 1995 and (d) 2011, as well as (e) surface flow speed of 2011 after smoothing, patching and being interpolated on Elmer/Ice mesh grid (Section 3.3). The underlay satellite image in (a) is a free product sample from TerraColor ${ }^{\circledR}$ Global Satellite Imagery (http://www. terracolor.net/). The insert at the upper left corner shows the ice cap's location within the Svalbard archipelago. The gray solid line marks Basin 3. Details about the coverage of ice thickness survey as well as surface and bedrock elevation can be found in Fig 5.5 and Fig. 5.2 , Dunse (2011), respectively.

southern part (Dunse and others, 2015). The acceleration then propagated inland to extend over the whole of Basin 3, destabilizing the entire terminus in autumn 2012 and reaching its maximum velocity in January 2013. Satellite observations show that the terminus advanced between 2010 and late 2012 and then the southern portion retreated more than $1 \mathrm{~km}$ after the southern flowing unit accelerated (McMillan and others, 2014; Dunse and others, 2015). The calving front continued advancing until July 2014 (personal communication with Thomas Schellenberger, Oslo University) after the deceleration of the fast flowing area.

In a previous model study Dunse and others (2011) suggested that a switch in basal temperature alone was not sufficient to generate surge behavior, which could only be achieved in combination with enhanced flow over marinegrounded ice, and simulated by a basal-sliding law parameterization representing soft, water-saturated sediments. Gladstone and others (2014) used steady-state models with different boundary conditions to hypothesize a soft-bedded sliding mechanism involving subglacial hydrology systems to explain both seasonal and interannual acceleration during the active surge phase. Both model studies have addressed the importance of time-evolving basal condition.

The switch between cold and temperate basal conditions could also explain the activation and deactivation of surge behavior. The feedback between ice thickness and basal temperature (Clarke, 1976; Dunse and others, 2011; Gladstone and others, 2014) can be split into different phases: (1) the build-up of the reservoir area of a glacier during its quiescent phase insulates the bed from the cold atmosphere and creates a temperate basal condition; (2) warming at the bed which increases basal sliding is enhanced by frictional heat generated by basal sliding itself; (3) temperate basal conditions may then expand towards the margins pushing the surge 
front forwards; (4) the dynamic thinning and flattening of the ice surface reduce thermal insulation and remove temperate basal conditions, bringing the glacier back to its quiescent phase. However, this feedback provides a mechanism for century-scale oscillations of a surge glacier that are much longer than the timescale suggested by most of the recent observations and model studies. A change of thermal regime may also affect the development of the surge phase of Basin 3 on shorter than centennial timescales through the feedback between basal temperature and hydrology systems. Dunse and others (2015) suggested a hydro-thermodynamic feedback that involves the presence of water at the bed from either surface or basal meltwater due to cryo-hydrological warming (Phillips and others, 2010, 2013). Soft-bed conditions influenced by the hydrology at the till/ice interface mentioned in Gladstone and others (2014) may also provide explanations for both seasonal and interannual acceleration in Basin 3.

McMillan and others (2014) suggested that changes in the terminus condition may also affect acceleration. The terminus thinned prior to the 2012 acceleration, which might have caused the southern terminus to float in hydrostatic equilibrium, however after the onset of the acceleration the upstream area thinned and the terminus thickened and dramatically advanced into the ocean (Dunse and others, 2015). Thus the change in basal conditions in southern Basin 3 may be due to changes upstream - such as water piracy from the northern part of the basin as it thinned (Tulaczyk and others, 2000), or a mechanism that involves calving front migration and changes in longitudinal stress gradient that propagate inland (Nick and others, 2009).

The mechanisms behind the surge in Basin 3 remain uncertain - how much does it reflect the internal nature of the glacier and how much does it reflect the external climate forcing? This is surely a key point in future projections of sea level contributions from land ice in Svalbard.

In this study we take Basin 3, Austfonna ice cap as a case in various transient simulations to assess the importance of basal boundary conditions, for example basal friction coefficient, for the observed changes in this area. The spatial variation of basal friction coefficient is obtained via inversion from surface velocities and in turn used as basal boundary condition in the transient simulations. SMB is downscaled from the relatively high resolution regional climate model (RCM) HIRHAM5 $(\sim 5.5 \mathrm{~km})$ to the finer resolution $(<2.5$ $\mathrm{km}$ ) of the IDM to drive local ice cap topographic evolution using a method based on SMB-elevation gradient. The reference transient simulation from January 1995 to December 2011 was performed using a full-Stokes IDM, with elevation-corrected SMB time series and linearly interpolated basal friction coefficient field over time, constrained by observed velocities in 1995 and 2011. We also deploy an IDM based on the vertically integrated stress balance of Schoof and Hindmarsh (2010), keeping the same boundary conditions and forcing, to examine the impact of model selection on ice cap response. Although none of the models have procedures to link surface processes with basal processes we try to explore the role of basal lubrication in model dynamics by using differing evolutions over time for the basal friction coefficient. In addition, we try to reproduce the dramatic speed-up in the southern part of Basin 3 from January 2012 to June 2013 (Dunse and others, 2015) by selectively altering the spatial distribution of the basal friction coefficient over different regions of the bed. The results show that both modeled velocities and volume change are governed by friction coefficient indicating the need for a processbased subglacial component to alter the basal friction through time regardless of the choice of IDMs.

\section{INPUT DATA}

\subsection{Surface and bedrock topography data}

We employ the surface and bedrock data of Dunse and others (2011) and provide here an overview over the various datasets and compilation procedures of Dunse (2011).

The digital elevation model (DEM) providing the surface elevation above sea level at $250 \mathrm{~m}$ resolution is based on the Norwegian Polar Institute (NPI) 1: 250000 topographic maps derived from aerial photography and airborne radioecho sounding (RES) measurements over Austfonna in 1983. The marine bathymetry ( $2 \mathrm{~km}$ horizontal resolution) is from International Bathymetry Chart of the Arctic Ocean, Version 2.0 (Jakobsson and others, 2008).

Ice thickness data are based on three different datasets: airborne RES data (covered by airborne traverses spaced a nominal $5 \mathrm{~km}$ apart) published by Dowdeswell and others (1986), $60 \mathrm{MHz}$ airborne RES data acquired by the Danish National Space Centre and $20 \mathrm{MHz}$ ground-penetrating radar (GPR) data collected by Vasilenko and others (2010) along profiles $\sim 800 \mathrm{~km}$ long, which follow the routes for mass-balance measurements made by the University of Oslo and NPI since 1998 (Schuler and others, 2007; Taurisano and others, 2007; Dunse and others, 2009) in the upper region and only cover the central flowline mapped by Dowdeswell and others (1999) in the lower region in Basin 3. The precision of the ice thickness measurements from the GPR profiling is estimated to be $\sim 1.6 \mathrm{~m}$. And the accuracy is determined by adding an absolute error of $\sim 0.3 \%$ ( $3 \mathrm{~mm}$ per meter ice) to the precision value (Dunse and others, 2012).

The surface elevation (Fig. 1a) and ice thickness data used in this study are then all resampled onto a $1.0 \mathrm{~km} \times 1.0 \mathrm{~km}$ grid mesh (Dunse, 2011). The averaging during the interpolating process creates a kind of mean state for the ice cap, which is not likely to be a dynamically steady state, as the ice cap has experienced thickening over its interior since the 1980s. Bedrock elevation (Fig. 1b) was derived by point-wise subtracting the ice thickness from the surface elevation. An interactive gridding scheme was applied to eliminate the mismatch between the bathymetry and the surface elevation along the southern and northwest coast line (Dunse, 2011). Errors in bedrock DEM along the coastline could affect the simulated velocity and the ice fluxes; however, as the calving front is fixed during the simulation, this cannot affect the stability of the terminus. However model setups allowing for terminus migration in future studies must consider potential DEM errors.

\subsection{Surface velocity data}

The horizontal surface velocity data used for basal friction coefficient inversion is based on satellite remote sensing measurements. The 1995 surface velocity field referred to in the following section is calculated using synthetic aperture radar interferometry (InSAR) from the Tandem Phase ERS-1/2 (European Remote Sensing Satellite) SAR observation 
obtained between December 1995 and January 1996, which is smooth and has good coverage (Dowdeswell and others, 2008) (Fig. 1c). The 2011 surface velocity field is calculated with a combined InSAR and tracking approach from ERS-2 SAR observations obtained between March and April 2011, which contain data gaps and regions with noisy error fields (Schäfer and others, 2014) (Fig. 1d). A more detailed description of the data can be found in Section 2.1.1 of Gladstone and others (2014).

\section{METHODOLOGY}

\subsection{Ice dynamic models}

We applied two widely-used and state-of-the-art IDMs to investigate the importance of model choice. The models differ in their approximations of the equations governing ice flow, as well as the numerical implementation strategies.

Elmer/lce (Gagliardini and others, 2013) utilizes the finiteelement method to solve the full-Stokes equations. The fullStokes model is set up on an unstructured mesh over the whole of Austfonna with horizontal resolution varying between $0.4 \mathrm{~km}$ and $2.5 \mathrm{~km}$ using an isotropic surfaceremeshing procedure Yams (Frey, 2011). Finer resolution is assigned to fast flowing areas as determined from velocity observations made in 2011 (over Basin 3) or 1995 (elsewhere on the ice cap). Finally, the mesh is vertically extruded between the interpolated bedrock and surface and divided into 10 equally spaced layers to form a terrain-following three-dimensional (3-D) mesh.

The BISICLES model (Cornford and others, 2013) employs a vertically integrated formulation similar to the one proposed by Schoof and Hindmarsh (2010), which takes into account the vertical shear strain by firstly solving for horizontal velocities with a 2-D stress-balance equation, and calculates vertical velocities that integrate effective viscosity and the vertical component of the deviatoric stress. The model equations are discretized using the finite volume method. BISICLES is capable of applying adaptive mesh refinement. However, here we use a constant-in-time structured mesh with $0.4 \mathrm{~km} \times 0.4 \mathrm{~km}$ resolution everywhere to avoid fluctuations in the calculated area of Basin 3 caused by changing local accuracy in discretization. As in Elmer/lce, the mesh is also extruded vertically into 10 equally spaced layers.

Transient simulations of both models are run without thermomechanical coupling: the ice temperature is kept constant in time at the temperature $T_{1995}$ specified in Section 3.3. Both models employ monthly time steps.

\subsection{SMB downscaling}

Two different ways of downscaling of climate forcing from the RCM HIRHAM5 (Christensen and others, 2007), which itself is forced with atmosphere and sea surface temperatures from ECMWF ERA Interim reanalysis (Rae and others, 2012), have been applied in this study. In both methods, monthly sums of daily SMB from the RCM time series from January 1995 to December 2011 are used.

In the first downscaling method ( $\left.S M B_{\text {elevcorr }}\right)$ SMB-elevation gradients are used, which are defined as the rates at which winter SMB and summer SMB change with elevation, assuming that local SMB-elevation gradients are able to predict the variability of surface energy balance that describes the SMB (Helsen and others, 2012). Alternatively, we directly project the HIRHAM5 SMB to the IDM grid points using inverse distance weighting ( $S M B_{\text {noelevcorr }}$ ) (IDW; Sherpard, 1968).

Despite the fact that surface water routing to the bed is thought likely to be critically important in the dynamical evolution of Austfonna (Gladstone and others, 2014; Dunse and others, 2015), SMB is not linked to basal processes in both methods and only effects the evolution of the ice geometry.

Elmer/lce solves an advection equation to allow the upper free surface $\left(z_{s}(x, y, t)\right)$ to evolve with time:

$$
\frac{\partial z_{\mathrm{s}}}{\partial t}+u_{\mathrm{s}} \frac{\partial\left(z_{\mathrm{s}}\right)}{\partial x}+v_{\mathrm{s}} \frac{\partial\left(z_{\mathrm{s}}\right)}{\partial y}-w_{\mathrm{s}}=b_{\mathrm{sfc}},
$$

where $\left(u_{\mathrm{s}}, v_{\mathrm{s}}, w_{\mathrm{s}}\right)$ are surface velocities obtained from the Stokes solution and $b_{\mathrm{sfc}}=b_{\mathrm{sfc}}(x, y, t)$ is SMB.

In BISICLES, ice thickness evolves with time by solving the vertically integrated advection equation:

$$
\frac{\partial h}{\partial t}+\frac{\partial\left(u_{\mathrm{s}} h\right)}{\partial x}+\frac{\partial\left(v_{\mathrm{s}} h\right)}{\partial y}=b_{\mathrm{sfc}}
$$

where $h$ is the ice thickness, $\left(u_{s}, v_{s}\right)$ are surface velocities from the flow solution and $b_{s f c}=b_{s f c}(x, y, t)$ is SMB. The upper surface elevation $z_{s}$ can be obtained by adding $h$ to the given bedrock elevation $z_{b}$ :

$$
z_{\mathrm{s}}=h+z_{\mathrm{b}}
$$

\subsection{Basal friction coefficient inversion}

A key variable in understanding the time evolution of the ice dynamics is the basal friction coefficient, particularly for Basin 3. Here we will outline the general procedure of the inversion of basal friction coefficients. We carry out inverse modeling only within Elmer/lce using a control method (MacAyeal, 1993; Morlighem and others, 2010), which is implemented in Elmer/lce by GilletChaulet and others (2012), to determine a basal friction coefficient field $(C)$ by minimizing the mismatch between modeled and observed surface velocity fields in 1995 and 2011.

Due to incomplete coverage and noise in the 2011 observations, we produce the 2011 Austfonna velocity field using the high-quality data available over Basin 3 for 2011 while the rest of the ice cap is kept to the velocity observed in 1995 - the same procedure was used by (Gladstone and others, 2014, figs 1c and e). The sliding relation is given by

$$
\tau_{\mathrm{b}}=C\left|u_{\mathrm{b}}\right|^{m-1} u_{\mathrm{b}}
$$

where $\tau_{\mathrm{b}}$ is the basal shear stress, $u_{\mathrm{b}}$ is the basal velocity, $m$ $(m=1)$ is the Weertman exponent and $C$ is the basal friction coefficient, which is represented as $C=10^{\beta}$ in the inversion method to avoid non-physical negative values. The optimization is done with respect to $\beta$.

We follow Gladstone and others (2014) in adopting an iterative process to accommodate ice temperatures in the flow solution, except for the points listed below:

We initialize the process by setting the basal shear stress equal to the gravitational driving stress, so that:

$$
\beta_{\text {init }}=\log _{10}\left(\rho_{i} g h\left|\nabla z_{s}\right|\left|u_{o b s}\right|\right),
$$


where $\beta_{\text {init }}$ is the initial exponent for the friction coefficient $C$, $\rho_{i}$ is the density of ice, $g\left(g=9.81 \mathrm{~m} \mathrm{~s}^{-2}\right)$ is the gravitational acceleration, $h$ is the ice thickness, $\nabla z_{\mathrm{s}}$ is horizontal gradient of the surface elevation a.s.l. and $u_{o b s}$ is the observed velocity:

A Dirichlet boundary condition for temperature is imposed at the upper boundary:

$$
T_{\text {surf }}=T_{\text {sea }}+\lambda z_{s}
$$

where $T_{\text {surf }}$ is the surface ice temperature, $T_{\text {sea }}\left(T_{\text {sea }}=-7.68^{\circ} \mathrm{C}\right)$ is the mean annual air temperature at sea level estimated from two weather stations on Austfonna during 2004 and 2008 (Schuler and others, 2014) and four weather stations on Vestfonna during 2008 and 2009 (Möller and others, 2011), $\lambda$ $\left(\lambda=0.004 \mathrm{~K} \mathrm{~m}^{-1}\right)$ is the lapse rate (Schuler and others, 2007) and $z$ is the surface elevation;

An initial temperature is prescribed:

$$
T_{\text {init }}=T_{\text {surf }}+\frac{q_{\text {geo }}}{\kappa} D
$$

where $T_{\text {init }}$ is the initial depth-dependent temperature profile based on the surface temperature $T_{\text {surf }}$ calculated from Eqn (6); $q_{g e o}$ is the geothermal heat flux, which we take as 40.0 $\mathrm{mW} \mathrm{m} \mathrm{m}^{-2}$ over Austfonna (Ignatieva and Macheret, 1991; Dunse and others, 2011; Schäfer and others, 2014); $\kappa(\kappa=$ $2.07 \mathrm{~W} \mathrm{~m}^{-1} \mathrm{~K}^{-1}$ ) is a representative heat conductivity of ice for the ice temperature range and $D$ is the distance from the upper surface.

The iterative process comprises four parts: initiate the inversion with $\beta_{\text {init }}$ and $T_{\text {init }}$ and invert for $\beta$ for the first time in steady-state simulation; carry out steady-state simulation for only thermodynamics using the velocities obtained from the inversion; do the steady-state inversion again using $\beta$ and $T$ derived from the previous simulations; repeat the iteration until the differences in $\beta$ and $T$ between two successive iterations fall below a given threshold.

The exponent of the friction coefficient for 1995 (henceforth $\beta_{1995}$ ) and 2011 (henceforth $\beta_{2011}$ ) inverted from velocity observations as well as the distributions and profiles of temperature relative to pressure melting point $\left(T_{p m p}\right.$, $273.15 \mathrm{~K}$ ) along a flow line in Basin 3, $T_{1995}$ and $T_{2011}$ corresponding to $\beta_{1995}$ and $\beta_{2011}$, are shown in Figure 2 . We solve the heat transfer as a steady-state problem during inverse modeling allowing the ice temperature to be fully consistent with the ice flow regime and providing the fixed temperature profile for the following transient simulations. The $T_{1995}$ and $T_{2011}$ summit surface temperatures are $\sim-10.7^{\circ} \mathrm{C}$ (Fig. 2), which is consistent with the near-surface borehole temperatures $\left(\sim-4{ }^{\circ} \mathrm{C}\right.$ to $\left.\sim-13.5{ }^{\circ} \mathrm{C}\right)$ measured at the summit in 1985 and 1987 (Zagorodnov and others, 1990, 2006).

Temperate bed conditions (i.e. at $T_{p m p}$ ) are closely correlated with the distribution of low basal friction/fast flowing areas because frictional heating at the bed along with geothermal heat are the main basal heat sources. As noted by Gladstone and others (2014), heat is advected away from the fast flowing areas. The steady-state temperatures would require far longer times to develop than the decades-long transient simulations done here. Hence we use $T_{1995}$ for all the subsequent transient simulations, neglecting any changes in ice cap internal temperatures. This is further justified since the calculated friction coefficient field is not an explicit function of temperature, and the sliding law we use in the transient simulations is not directly linked to temperature, so there is no short-term (decadal) influence on the evolution of sliding imposed by this simplification.

\section{RESULTS}

Firstly, we carried out a 17 years transient run (204-month from January 1995 to December 2011), which is treated as a reference simulation when assessing the transient behavior sensitivities in ice dynamic simulations, using different IDMs ('MC') and time evolving $C$ field (denoted 'BC' in Table 1) for the entire Austfonna domain. The downscaling method of the $\mathrm{SMB}$ - to no surprise - turned out to have no significant influence on the results for the timescales of our study (Fig. 4). Consequently we use $S M B_{\text {elevcorr }}$ for reference simulation,
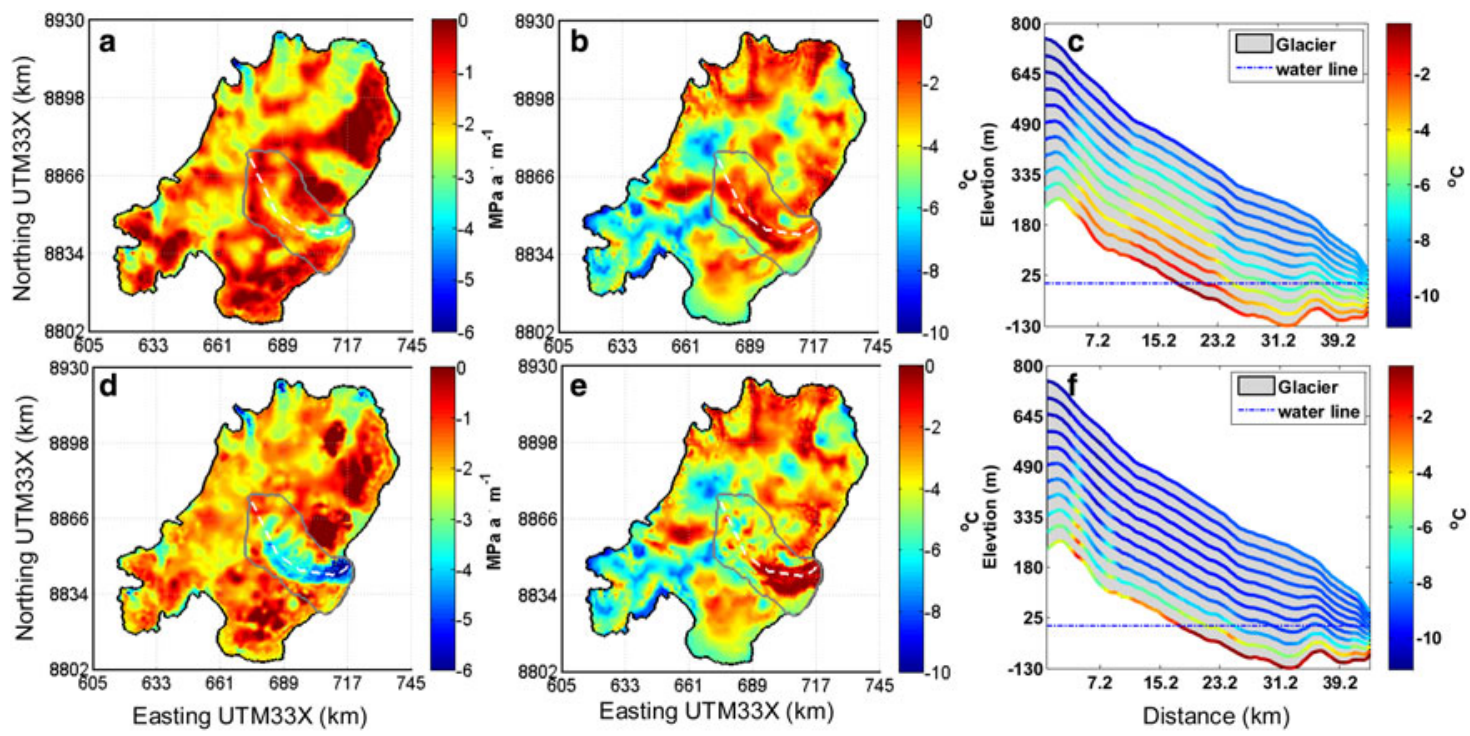

Fig. 2. (a) The inverted distribution of the exponent ( $\beta$ ) of basal friction coefficient $(C)$ from 1995 observed surface velocities, (b) the corresponding distribution of temperature deviations from pressure melting point and (c) the profile of temperature deviations along the white dash line from steady state simulation. Panels (d), (e) and (f), show the corresponding results for the 2011 velocity inversion. The gray solid line marks Basin 3. 
Table 1. Experimental design

\begin{tabular}{|c|c|c|c|c|c|}
\hline Name & IDM & $\mathrm{C}$ & $\mathrm{SMB}$ & Initial topography & Simulation duration \\
\hline Ref. & Elmer/lce & $C_{\text {linear }}$ & $\mathrm{SMB}_{\text {elevcorr }}$ & 1995 & 204 months (Jan 1995-Dec 2011) \\
\hline $\mathrm{MC}$ & BISICLES & $C_{\text {linear }}$ & $\mathrm{SMB}_{\text {elevcorr }}$ & 1995 & 204 months (Jan 1995-Dec 2011) \\
\hline $\mathrm{BC}$ & Elmer/lce & $C_{\text {step1995 }}$ and $C_{\text {step2011 }}$ & $\mathrm{SMB}_{\text {elevcorr }}$ & 1995 & 204 months (Jan 1995-Dec 2011) \\
\hline BE & Elmer/lce & $C_{\text {linearextap, }} C_{\text {nofric } 1}$ and $C_{\text {nofric } 2}$ & $\mathrm{SMB}_{90 \mathrm{~s}}$ & 2012 & 16 months (Jan 2012-May 2013) \\
\hline
\end{tabular}

Ref., the reference simulation; $\mathrm{MC}$, the experiment designed to investigate the sensitivity of transient behavior to model choice; $\mathrm{BC}$, the experiment designed to investigate the sensitivity of transient behavior to basal boundary condition $(C)$; $B E$, the experiment designed to investigate the possible mechanism triggering the drastic acceleration of the southern part of Basin 3 starting from autumn 2012.

$M C$ and $\mathrm{BC}$ simulations. We varied just one of those two components while keeping the other as described in the reference simulation; their anomalies relative to the reference simulation are detailed in the following sections.

In addition, we also carried out simulations to investigate the role of changing basal friction in the recent surge in southern Basin 3 that started in autumn 2012. We use the mean 1990-2000 SMB field projected by IDW as climatic forcing since we do not have SMB time series from the $\mathrm{RCM}$ for this time period.

\subsection{Reference transient simulation}

The reference simulation is performed with the full-Stokes IDM Elmer/lce and employs the topographically corrected $\mathrm{SMB}$ field $\left(S M B_{\text {elevcorr }}\right)$. We choose a time evolving scenario for the friction coefficient, $C_{\text {linear, }}$ which prescribes the locally linear temporal transition between $C_{1995}$ and $C_{2011}$ (from 1995 to 2011). We think that this combination stands for the best available choice for transient simulations of Basin 3 with the given input data; however, we cannot claim that this represents the most realistic simulation due to the lack of the representations of certain physical processes in the model, which will be discussed in Section 5.

Figure 3 shows the absolute and relative error between the modeled and post-processed observational surface flow speed (Fig. 1e) over Basin 3 at the end of the transient simulation in 2011:

$$
\begin{aligned}
& \varepsilon=\left|u_{\text {mod }}\right|-\left|u_{o b s}\right|, \\
& \eta=\frac{|\varepsilon|}{\left|u_{o b s}\right|} \times 100 \%
\end{aligned}
$$

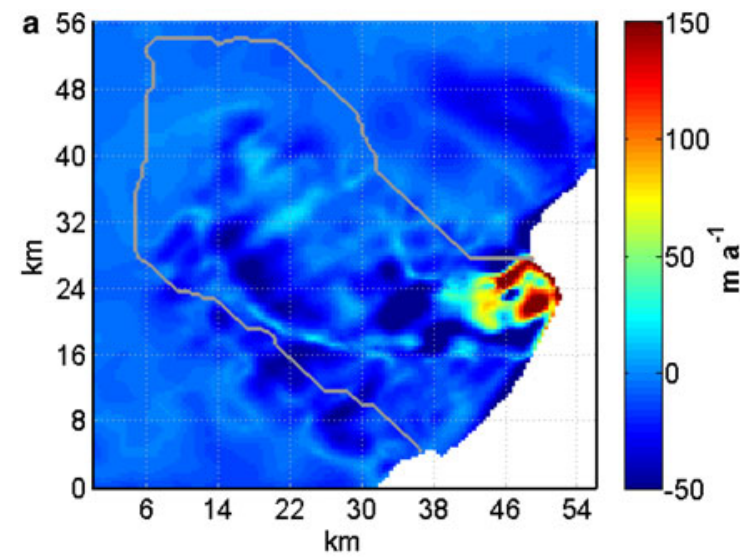

where $\varepsilon$ and $\eta$ are the absolute and relative errors respectively, $u_{\text {mod }}$ is the modeled surface velocity and $u_{o b s}$ is the observational surface velocity.

Relative errors are lowest over the fast flowing area. The errors are mainly introduced by the inverted basal friction coefficient as the fast flow is mainly due to basal sliding with ice deformation accounting for only $\sim 5 \mathrm{~m} \mathrm{a}^{-1}$ over Austfonna (Dowdeswell and others, 1999). The simulated volume change rate in water equivalent (w.e.) of the entire ice cap for the period 2002-08 is $-0.45 \mathrm{~km}^{3} \mathrm{a}^{-1}$ (w.e.) (Fig. 4). However, the observed volume change rate is -1.3 $\pm 0.5 \mathrm{~km}^{3} \mathrm{a}^{-1}$ (w.e.) (Moholdt and others, 2010) when taking into account the ice loss of $\sim 1.4 \mathrm{~km}^{3} \mathrm{a}^{-1}$ (w.e.) caused by rapid retreat of the calving front (Dowdeswell and others, 2008). The difference between the observations and the model results is therefore likely to be caused by a fixedfront calving criterion, that is, the calving front can neither advance nor retreat, and the thickness of the calving front is set in balance with the hydrostatic pressure from the ocean. Thus the contribution of calving flux to mass loss calculated here only accounts for the ice flux towards the calving front that is not related to front advance or retreat, which in the case of the simulation of Basin 3 means a thickening of the calving front. Treatment of calving is a difficult problem, though progress may be made by considering discrete-particle simulations of the ice fracture process (Åström and others, 2013) with realistic geometry. From January 2002 to December 2011 the simulated volume loss of Austfonna is $\sim 8.6 \mathrm{~km}^{3}$ of which $\sim 32 \%$ comes from Basin 3 .

\subsection{Sensitivity to model choice}

Figure 5 shows the modeled surface flow speed of Basin 3 at the end of the MC simulation (Table 1) as well as the

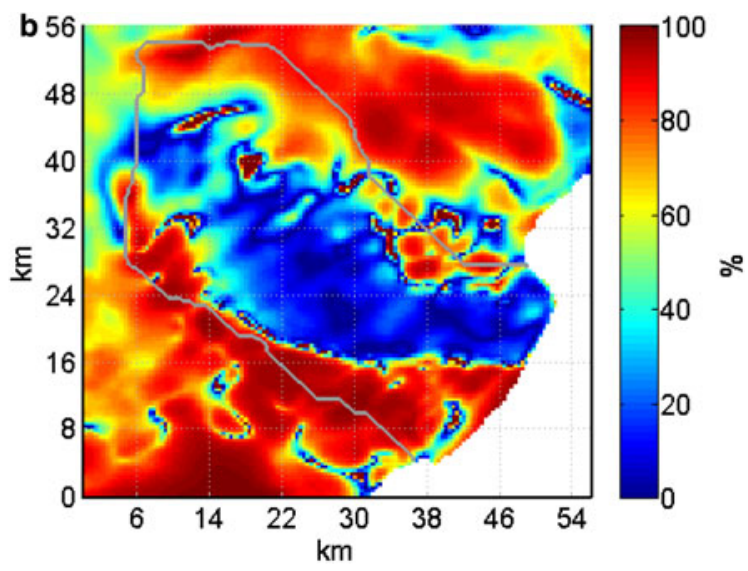

Fig. 3. (a) The absolute and (b) relative error between the modeled and observed surface flow speed at Basin 3 in 2011. The gray solid line marks Basin 3. 


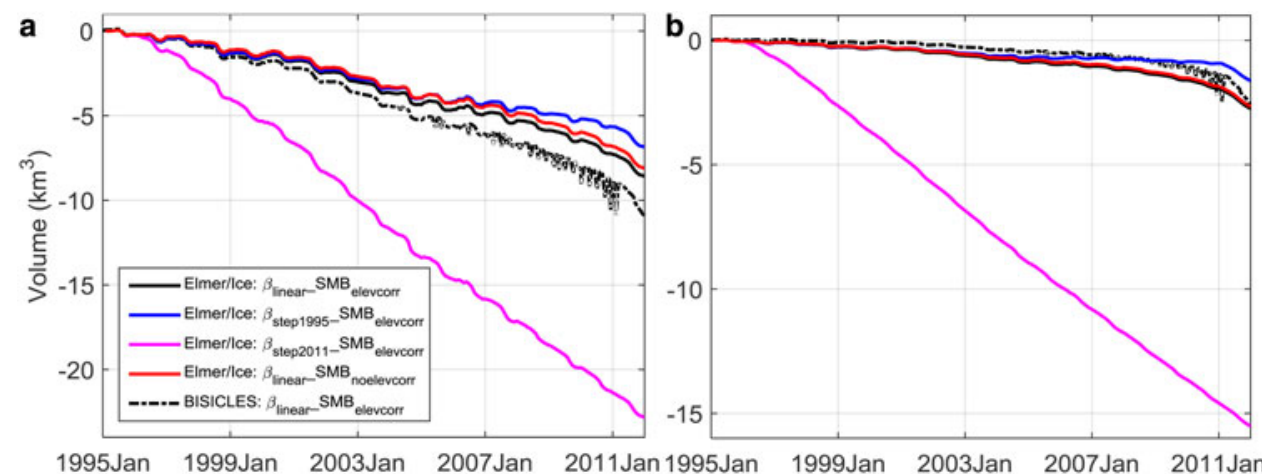

Fig. 4. The volume change of (a) Austfonna ice cap and (b) the outlet glacier in Basin 3 over time.

reference simulation. The location of the fast flowing area is the same for both Elmer/lce and BISICLES because the same initial geometry and time-evolving $C$ fields are used. BISICLES produces relatively higher flow velocities close to the calving front of the northern outlet. The divergence between the two models as the simulation progresses can be clearly seen in the flow line snapshots in Figure 6. The BISICLES surface flow speeds gradually surpass those of Elmer/lce after 120 months (in January 2005) but only become significantly higher in the final 12 months (January-December 2011). In other words, BISICLES is more sensitive to decreasing $C$ than Elmer/lce.

The mass loss over the entire Austfonna ice cap in BISICLES simulations exceeds that of Elmer/lce by $2.25 \mathrm{~km}^{3}$ by the year 2011. However, mass loss from Basin 3 is less in BISICLES than in Elmer/lce. BISICLES produces thicker ice at the calving front than Elmer/lce (Fig. 6), but as both models use the same fixed-front calving scheme, the difference in mass flux may be from surface elevation feedbacks that differ due to the different simplification of the stress balance equation adopted in these two models.

\subsection{Sensitivity to basal friction coefficient}

Earlier studies using inverse methods (Gillet-Chaulet and others, 2012; Gladstone and others, 2014; Schäfer and others, 2014) have shown that a spatially variable basal friction coefficient was needed to reproduce the observed surface velocities over complex terrains. The observational surface velocity fields show a significant acceleration of Basin 3 from 1995 to 2011, and the recent observations of a full surge show that acceleration continued until at least 2013 (Dunse and others, 2012, 2015). To capture the change of the velocity field in a transient simulation, temporal change of the $C$ field based on knowledge of the underlying physical processes would be required. Lacking a process-based model that computes the temporal evolution of the basal friction conditions based on factors such as basal hydrology (Gladstone and others, 2014), we evolve the basal friction field in two further ways, constrained by the inversions obtained for $1995\left(C_{1995}\right)$ and $2011\left(C_{2011}\right)$. Keeping other conditions the same as for the reference simulation, we vary the $C$ field using the scenarios employed in the BC simulations (Table 1) over the 204 months period:

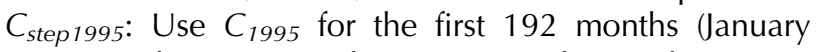
1995-December 2010) and instantaneously switch to $C_{2011}$ for the rest (January 2011-December 2011);

$C_{\text {step2011: }}$ Use $C_{1995}$ for the first 12 months (January 1995December 1995) and instantaneously switch to $C_{2011}$ for the rest (January 1996-December 2011).

Figure 7 shows snapshots of the evolution of the surface flow speed along the flowline (Fig. 2). The abrupt change in basal friction coefficient distribution in both $C_{\text {step2011 }}$ and $C_{\text {step } 1995}$ brings about a corresponding change in the velocity (in 1995 in the first case and 2011 in the second), with flow velocities speeding up by a factor of four near the calving front. At the same time, a linear transition from $C_{1995}$ to $C_{2011}\left(C_{\text {linear }}\right.$ ) leads to a temporally smooth transition a

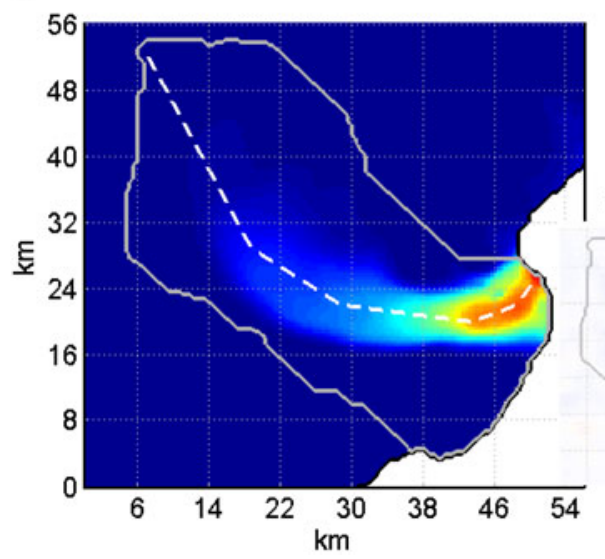

b

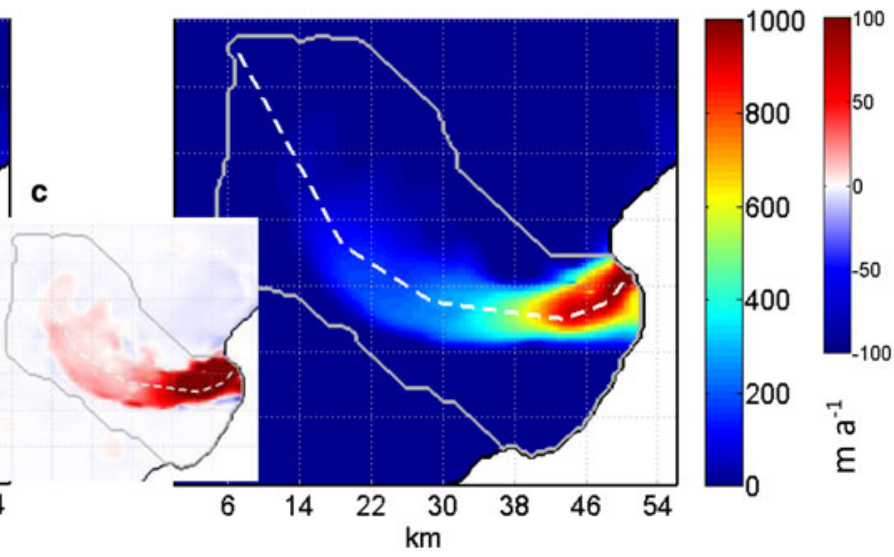

Fig. 5. The modeled surface flow speeds in December 2011 given by (a) Elmer/lce, (b) BISICLES for the MC simulation (Table 1) (color bar on the left; in $\mathrm{m} \mathrm{a}^{-1}$ ) and (c) the difference between BISICLES and Elmer/lce (the reference) modeled surface flow speeds (color bar on the right; in $\mathrm{m} \mathrm{a}^{-1}$ ). The gray solid line marks Basin 3 . 


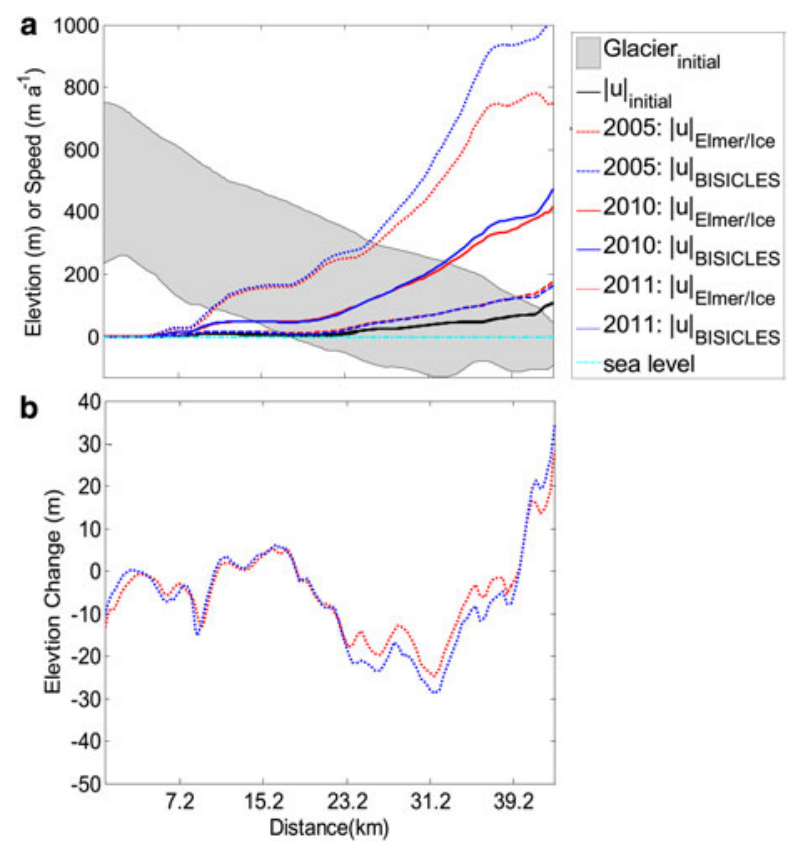

Fig. 6. (a) The modeled speed and (b) surface elevation change simulated by Elmer/lce (red) and BISICLES (blue) along the white flow line (Fig. 2) for the MC simulation in January 2005 (dashed line), January 2010 (solid line) and December 2011 (dotted line). The black solid line shows the modeled speed in 1995.

between the 1995 and 2011 flow speeds. The difference between these simulations by 2011 is far less pronounced: the most obvious difference is slower flow near the front $\sim 600 \mathrm{~m} \mathrm{a}^{-1}-$ in $C_{\text {step2011 }}$ compared with $800 \mathrm{~m} \mathrm{a}^{-1}$ in the other two cases, due to the longer period of elevated discharge and hence a lower surface elevation by 2011.

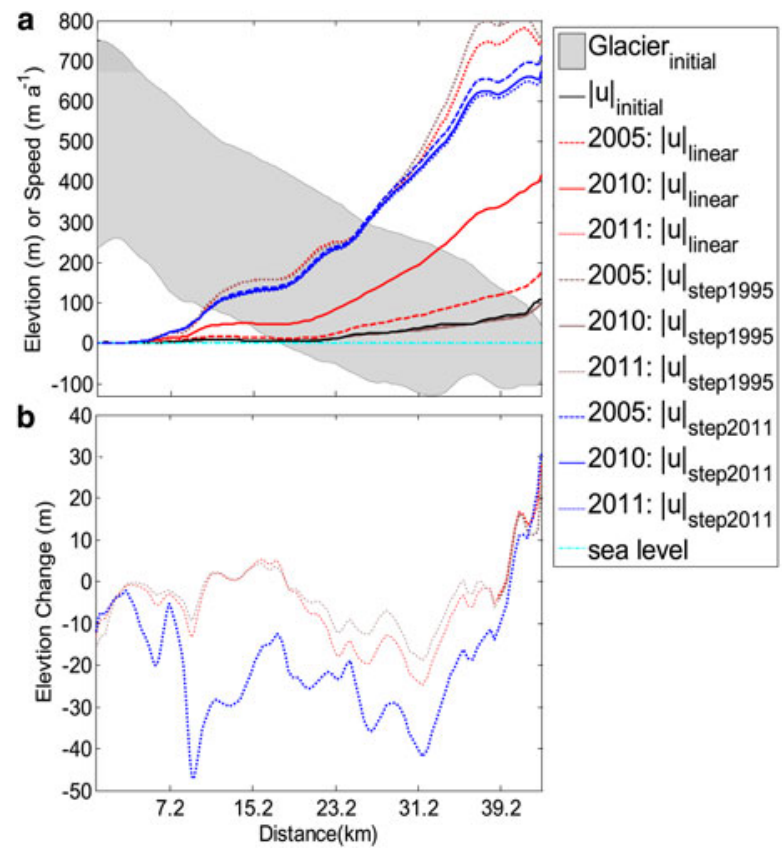

Fig. 7. As for Figure 6 but for the reference and BC simulations (Table 1). (a) Modeled speed and (b) surface elevation change of

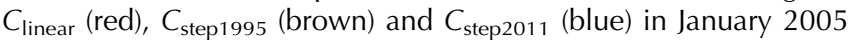
(dashed lines), January 2010 (solid line) and December 2011 (dotted lines). The black solid line shows the modeled speed in 1995.
Observations of Basin 3 since 2008 (Dunse and others, 2015) exhibit partially reversible stepwise multiannual acceleration of Basin 3; these are sudden speedup events coincident with the summer melt seasons, each of which requires rapid changes of the basal condition ( $C$ distribution) for the fast flowing area.

In the experiment deploying $C_{\text {step2011, a dramatic mass }}$ loss occurs after the $C$ field is switched which exceeds that of the reference simulation by a factor of 2.6 by the end of the simulation. On the other hand, the volume loss for the whole of Austfonna under the $C_{\text {step } 1995}$ scenario is $1.8 \mathrm{~km}^{3}$ less than $C_{\text {step2011 }}$ scenario (Fig. 4).

\subsection{The role of friction coefficient in the recent acceleration of southern Basin 3}

Inspired by the sensitivity tests and the recently published observations (Dunse and others, 2015) we carried out additional simulations to investigate the role of changing basal friction in the recent surge in southern Basin 3 that started in autumn 2012, by linearly extrapolating the evolution of the $C$ field obtained for the year 2011 over Basin 3 using the $C_{1995}$ to $C_{2011}$ time gradient for each point. We also changed the initial values of $C$ in two different regions of the southern part of Basin 3 (Fig. 8) to a relatively low friction condition $\left(C=10^{-4} \mathrm{MPa} \mathrm{a} \mathrm{m^{-1 }}\right)$ while keeping the northern part the same as the inverted value from 2011 velocity. We then linearly reduced $C$ of the southern low friction area to a near zero friction condition $\left(C=10^{-30} \mathrm{MPa} \mathrm{a} \mathrm{m}^{-1}\right)$ over the course of the simulation. Thus three simulations are carried out for the 17 months from January 2012 to June 2013 (Table 1):

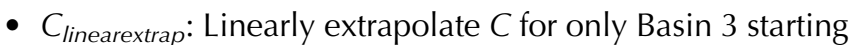
from $C_{2011}$ between January 2012 and June 2013 using the $C_{1995}$ to $C_{2011}$ gradient and constrained by a minimum value of $10^{-30} \mathrm{MPa} \mathrm{a} \mathrm{m}{ }^{-1}$ and keep $C_{2011}$ elsewhere;

- $C_{\text {nofrc } 1}$ : Linearly change $C$ from a spatially homogeneous value of $10^{-4} \mathrm{MPa} a \mathrm{~m}^{-1}$ to $10^{-30} \mathrm{MPa} \mathrm{a} \mathrm{m}^{-1}$ between

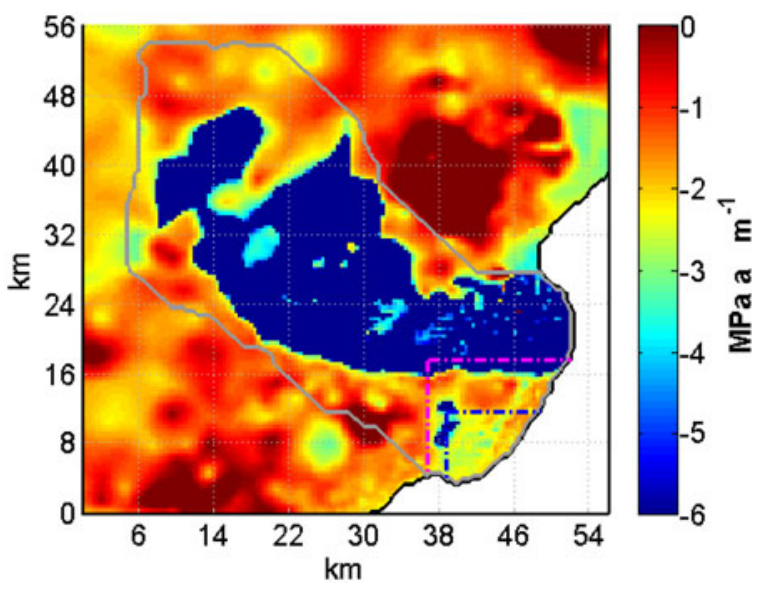

Fig. 8. The exponent $(\beta)$ of linearly extrapolated basal friction coefficient $(C)$. The color-coded map shows the $\beta$ from the reference simulation in February 2013 where the dark blue corresponds to the minimum values $C=10^{-30} \mathrm{MPa} \mathrm{a} \mathrm{m}^{-1}$. The area confined by the blue and pink dash-dotted lines indicate the region where $C$ is initially changed to $10^{-4} \mathrm{MPa} \mathrm{a} \mathrm{m}^{-1}$ and reduced to $10^{-30} \mathrm{MPa} \mathrm{a} \mathrm{m}^{-1}$ from January 2012 to June 2013 in $C_{\text {nofrc1 }}$ and $C_{\text {nofrc2 } 2}$ cases, respectively. The gray solid line marks Basin 3. 
January 2012 and June 2013 for the area between the blue line and the calving front in Figure 8, while keeping $C_{2011}$ elsewhere. The area where $C_{\text {nofrc } 1}$ is applied matches the area in the southern Basin 3 where the sudden acceleration in April 2012 was observed (Dunse and others, 2015);

- $C_{\text {nofrc } 2}$ : As for $C_{\text {nofrc } 1}$ but for the larger area, between the pink line and the calving front in Figure 8, and keep to $C_{2011}$ elsewhere.

The linear extrapolation reduces $C$ in most of the northern fast flowing units to close to $10^{-30} \mathrm{MPa} \mathrm{a} \mathrm{m}{ }^{-1}$ within 12 months. Consequently, the formerly fast flowing unit in the northern part of Basin 3 accelerates dramatically to $\sim 6400$ $\mathrm{m} \mathrm{a}^{-1}\left(17 \mathrm{~m} \mathrm{~d}^{-1}\right)$ by the end of the simulation, which is comparable with the observed maximum surging speed in 2013 $\left(20 \mathrm{~m} \mathrm{~d}^{-1}\right)$ (Dunse and others, 2015). This near zero basal shear stress (i.e. minimal basal frictional drag) most resembles the situation of ice separated from its bedrock due to the presence of basal water at, or exceeding, full ice overburden pressure (Weertman, 1957; Kamb, 1970, Nye, 1970). However, the southern part of Basin 3 only accelerates to $\sim 90 \mathrm{~m} \mathrm{a}^{-1}\left(0.25 \mathrm{~m} \mathrm{~d}^{-1}\right)$ by January 2013 (Fig. 9). This is because the low friction area in southern Basin 3 is rather far inland and certainly cannot produce the observed acceleration near the terminus. Thus a simple continuation of the $C_{1995}$ to $C_{2011}$ basal friction trend and spatial pattern cannot reproduce the sudden acceleration of southern Basin 3.

By reducing $C$ from $10^{-4} \mathrm{MPa}$ a m $\mathrm{m}^{-1}$ to $10^{-30} \mathrm{MPa} \mathrm{a} \mathrm{m}^{-1}$ close to the terminus in the southern part of Basin 3 (the pink and blue areas in Fig. 8) we manage to produce a gradual acceleration there in both the $C_{\text {nofrc } 1}$ and $C_{\text {nofrc } 2}$ cases. This behavior is not produced unless the initial value of $C$ in the pink or blue areas is reduced from the $C_{2011}$ values to $10^{-4} \mathrm{MPa} \mathrm{a} \mathrm{m}{ }^{-1}$. Although the modeled surface flow speed of the $C_{\text {nofrc } 1}$ case in February 2013 is comparable with the maximum observed surging speed, the acceleration does not spread across the entire basin (Fig. 9b). Several tests with various larger areas with reduced basal friction in southern Basin 3 have been carried out (not shown), but only the distribution defined in $C_{\text {nofrc2 }}$ can produce an accelerating area that is comparable with the observed basin-wide surge area. In the $C_{\text {nofrc } 2}$ case, where the imposed low-friction region overlaps with that of the fast flowing northern flow unit, the acceleration expands to the entire basin but leads to higher velocities than the maximum observed surging speed (Fig. 9c).

\section{DISCUSSION AND CONCLUSIONS}

Observations of the outlet glacier in Basin 3, Austfonna revealed a discrete, multiannual stepwise acceleration in its northern basin since 2008 (Dunse and others, 2015) as a continuation of a gradual acceleration started in 1991 (Dowdeswell and others, 1999), followed by a recent sudden speedup of its southern basin starting in early 2012 (Dunse and others, 2015). We investigated how different representations of the temporal evolution of the spatial basal friction coefficient succeed in capturing the evolving dynamics of Basin 3, i.e., ice volume change in Austfonna over a period of 17 years and 40-fold changes of the surface flow speed. We also compare the influence of ice dynamics and volume change by using different IDMs.

The comparison between the results from the studies indi-

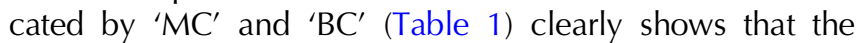
dynamic response of the fast flowing area in Basin 3 in the model simulations is governed by the temporal evolution of basal friction coefficient. Ice volume flux and sea-level rise contribution also depend most strongly on the choice of the basal friction coefficient evolution. As mentioned earlier, the choice of SMB downscaling method has no significant impact over the 17 years of simulation time. Similarly, the model physics, with both models including horizontal normal and shear stresses, appears to be less critical.

The BISICLES IDM produces generally higher flow speeds over Basin 3 than the Elmer/lce model when using the same basal friction coefficient field. That is consistent with the
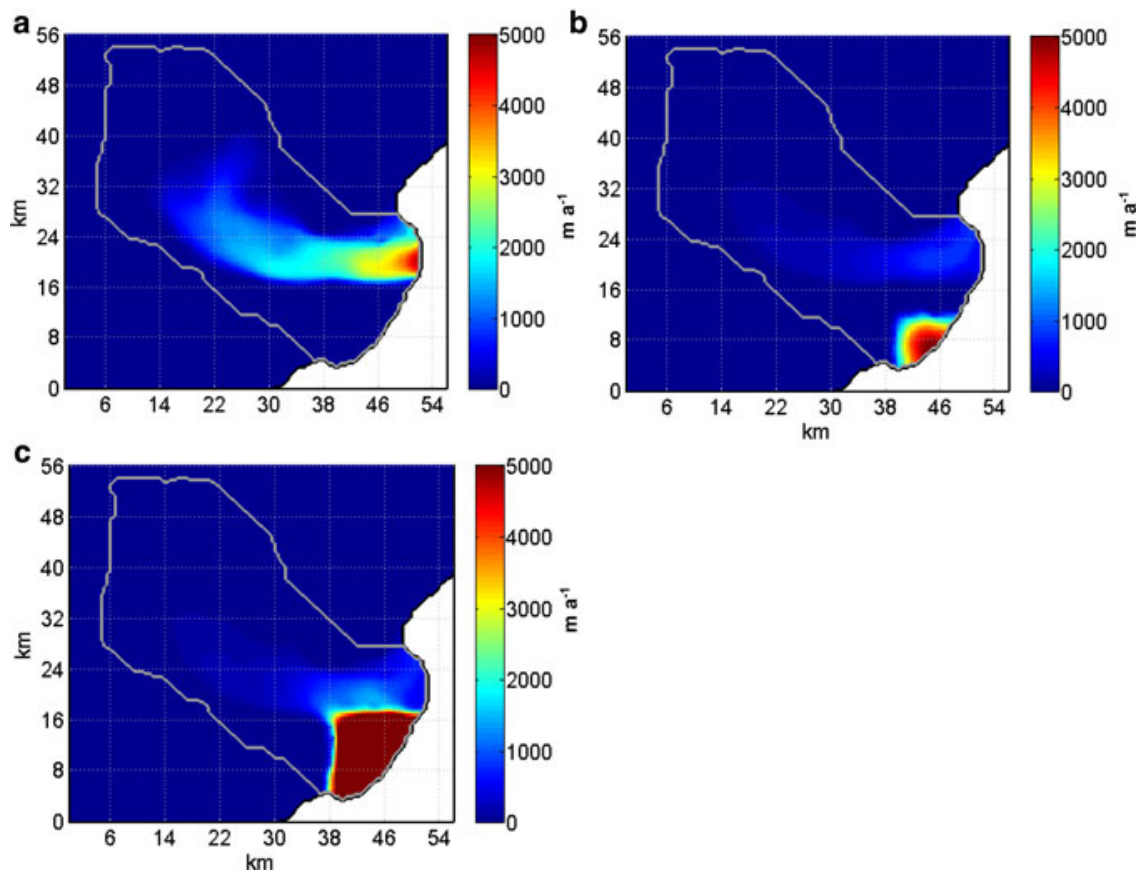

Fig. 9. The modeled surface flow speed in January 2013 for (a) $C_{\text {linearextrap }}$ (b) $C_{\text {nofrc1 }}$ and (c) $C_{\text {nofrc2 }}$. 
results in experiment P75D of the MISMIP3d model intercomparison showing that BISICLES produces slightly higher flow speed than Elmer/lce when using the same initial conditions in the steady-state simulations (Pattyn and others, 2013). The differences could be due to the additional stress components in the full-Stokes equation solved by Elmer/ Ice, namely the bridging stresses, which produce more buttressing from the fast flowing outlet units, but could also be related to the inclusion of simplified (and over estimated) vertical shear strains in the effective viscosity. As the basal friction coefficient field is inverted in the fullStokes IDM, this effect will have been partially prescribed in the BISICLES simulation. The complex geometry used in the simulation may also create inconsistencies via non-physical factors such as interpolation schemes or the numerical methods employed by the two IDMs.

Although the response of the modeled ice flow in Basin 3 is insensitive to the different $\mathrm{SMB}$ downscaling methods we used in these specific decadal timescale transient simulations, the SMB-elevation gradient method we favoured - and which did produce a more realistic SMB distribution - is designed to allow asynchronous coupling of a RCM with an IDM. The advantages of the method should be more noticeable in steep topography, for example in many coastal regions, or over millennial periods such as glacial/interglacial transitions (Helsen and others, 2012; Schäfer and others, 2015). The choice of the RCM downscaling method may also become crucial when linking the process of surface melt to basal hydrology in future model development.

Previous studies (Dunse and others, 2011, 2015; Gladstone and others, 2014) addressed the importance of both basal processes and the climatic driving force acting on the ice upper boundary (specifically, surface melting) in explaining the underlying physics of the surge in Basin 3. In our study, the governing effect of basal friction coefficient on both modeled velocities and volume change indicates the need for a process-based subglacial component to alter the basal friction through time regardless of the choice of IDMs. A soft-bed mechanism that involves the basal hydrology system and till deformation could be a future model development that may explain the surge in northern Basin 3 (Gladstone and others, 2014). In addition the missing link between climatic driving force and basal sliding, namely the representation of processes for routing surface meltwater down to the glacier bed in IDMs, would improve our ability to evaluate the impact of surface boundary condition changes (climate forcing) on model results.

Simply preserving the basal friction coefficient spatial pattern in our simulations cannot reproduce the observed surge acceleration pattern spanning from January 2012 to June 2013. Hence, the models require some method of specifying how basal friction changes during the course of the surge itself as a result of certain feedback mechanisms.

Furthermore unlike the stepwise acceleration of the northern unit that has lasted two decades, the abrupt speedup in the southern basin could be initiated by a different mechanism, which might be linked to the changes in the terminus. Future model development about ice front migration might be needed. The bed topography profile (Fig. 1) shows that the southern and middle flow units rest on a relatively flat or even on slightly reversed slopes. In contrast the northern basin has an undulating bed, which would likely lead to contrasting basal hydrology and roughness and thus to differences in calving front migration such as a marine ice-sheet instability (Schoof, 2007). This emphasizes the importance of accurate coastal bedrock topography in future simulations of calving front migration. Last but not the least, it is clear that the eventual basin-wide surge is a result of the merging of the southern fast flowing unit with the northern one.

\section{ACKNOWLEDGEMENTS}

We wish to thank all the partners for providing data and constructive discussion during the study, especially Ruth Mottram from Danish Meteorological Institute for the HIRHAM5 surface mass-balance time series, Tazio Strozzi from GAMMA Remote Sensing and Consulting AG for the remotesensing surface velocity data, Thomas Schuler from the University of Oslo for the September 2003 to August 2004 reference surface mass-balance data and Thorben Dunse from the University of Oslo for the bedrock and surface elevation data. We wish to thank Fabien GilletChaulet from Laboratoire de Glaciologie et Géophysique de l'Environnement for making available his code for the inverse modelling. We also acknowledge CSC-IT Center for Science Ltd. for the allocation of computational resources. Yongmei Gong is funded by project SVALI and European Science Foundation project Micro-DICE. This publication is contribution No. 74 of the Nordic Centre of Excellence SVALI funded by the Nordic Top-level Research Initiative. Rupert Gladstone is funded from the European Union Seventh Framework Programme (FP7/ 2007-2013) under grant agreement no. 299035.

\section{REFERENCES}

Åström JA and 6 others (2013) A particle based simulation model for glacier dynamics. Cryosphere, 7, 1591-1602 (doi: 10.5194/tc-71591-2013)

Bamber J, Krabill W, Raper V and Dowdeswell J (2004) Anomalous recent growth of part of a large Arctic ice cap: Austfonna, Svalbard. Geophys. Res. Lett., 31, L12402 (doi: 10.1029/ 2004GL019667)

Christensen $O$ and 6 others (2007) The HIRHAM regional climate model Version $5(\beta)$. Danish Climate Centre, Danish Meteorological Institute Technical Report no. 06-17

Clarke G (1976) Thermal regulation of glacier surging. J. Glaciol., 16, 231-250

Cornford S and 8 others (2013) Adaptive mesh, finite volume modeling of marine ice sheets. J. Comput. Phys., 232, 529-549 (doi: 10.1016/j.jcp.2012.08.037)

Dowdeswell J and 5 others (1986) Digital mapping of the Nordaustlandet ice caps from airborne geophysical investigations. Ann. Glaciol., 8, 51-58

Dowdeswell J, Unwin B, Nuttall A and Wingham D (1999) Velocity structure, flow instability and mass flux on a large Arctic ice cap from satellite radar interferometry. Earth Planet. Sci. Lett., 167, 131-140 (doi: 10.1016/S0012-821X(99)00034-5)

Dowdeswell J, Benham T, Strozzi T and Hagen JO (2008) Iceberg calving flux and mass balance of the Austfonna ice cap on Nordaustlandet, Svalbard. J. Geophys. Res., 113, 1-12 (doi: 10.1029/2007JF000905)

Dunse T (2011) Glacier dynamics and subsurface classification of Austfonna, Svalbard: Inferences from observations and modelling. (Dissertation submitted for the degree of Philosophiae Doctor (PhD), University of Oslo)

Dunse T and 5 others (2009) Recent fluctuations in the extent of the firn area of Austfonna, Svalbard, inferred from GPR. Ann. Glaciol., 50, 155-162

Dunse T, Greve R, Schuler T and Hagen JO (2011) Permanent fast flow versus cyclic surge behaviour: numerical simulations of 
the Austfonna ice cap, Svalbard. J. Glaciol., 57, 247-259 (doi: 10.3189/002214311796405979)

Dunse T, Schuler T, Hagen JO and Reijmer C (2012) Seasonal speedup of two outlet glaciers of Austfonna, Svalbard, inferred from continuous GPS measurements. Cryosphere, 6, 453-466 (doi: $10.5194 /$ tc-6-453-2012)

Dunse T and 5 others (2015) Glacier-surge mechanisms promoted by a hydro- thermodynamic feedback to summer melt. Cryosphere, 9, 197-215 (doi: 10.5194/tc-9-197-2015)

Edwards T and 12 others (2014) Effect of uncertainty in surface mass balance-elevation feedback on projections of the future sea level contribution of the Greenland ice sheet. Cryosphere, 8, 195-208 (doi: 10.5194/tc-8-195-2014)

Frey PJ (2001) YAMS A fully Automatic Adaptive Isotropic Surface Remeshing Procedure. RT-0252, INRIA

Gagliardini O, Cohen D, Raback P and Zwinger T (2007) Finiteelement modeling of subglacial cavities and related law. J. Geophys. Res., 112 (doi: 1029/2006JF000576)

Gagliardini O and 14 others (2013) Capabilities and performance of Elmer/lce, a new-generation ice sheet model. Geosci. Model Dev., 6, 1299-1318 (doi: 10.5194/gmd-6-1299-2013)

Gillet-Chaulet F and 8 others (2012) Greenland ice sheet contribution to sea-level rise from a new-generation ice-sheet model. Cryosphere, 6, 1561-1576 (doi: 10.5194/tc-6-1561-2012)

Gladstone R and 7 others (2014) Importance of basal processes in simulations of a surging Svalbard outlet glacier. Cryosphere, 8, 1393-1405 (doi: 10.5194/tc-8-1393-2014)

Gong Y, Cornford S and Payne A (2014) Modelling the response of the Lambert Glacier-Amery Ice Shelf system, East Antarctica, to uncertain climate forcing over the 21st and 22nd centuries. Cryosphere, 8, 1057-1068 (doi: 10.5194/tc-8-1057-2014)

Helsen $M$, van de Wal R, van de Broeke $M$, van de Berg W and Oerlemens J (2012) Coupling of climate models and ice sheet models by surface mass balance gradients: application to the Greenland Ice Sheet. Cryosphere, 6, 255-272 (doi: 10.5194/tc6-255-2012)

Ignatieva IY and Macheret YY (1991) Evolution of Nordaustlandset ice caps in Svalbard under climate warming. IAHS Publ., 208 (Symposium at St. Petersburg 1990 - Glacier-OceanAtmosphere Interactions), 301-312

Jakobsson $M$ and 7 others (2008) An improved bathymetric portrayal of the Arctic Ocean: implications for ocean modeling and geological, geophysical and oceanographic analyses. Geophys. Res. Lett., 35, L07602

Kamb B (1970) Sliding motion of glaciers: theory and observation. Rev. Geophys., 8, 673-728

Lefauconnier B and Hagen JO (1991) Surging and calving glaciers in Eastern Svalbard. Nor. Polarinst. Meddelelser., 116, 130

MacAyeal D (1993) A tutorial on the use of control methods in icesheet modeling. J. Glaciol., 39, 91-98

McMillan M and 14 others (2014) Rapid dynamic activation of a marine-based Arctic ice cap. Geophys. Res. Lett., 41, 8902-8909

Möller M and 7 others (2011) Climatic mass balance of the ice cap Vestfonna, Svalbard: a spatially distributed assessment using ERA-Interim and MODIS data. J. Geophys. Res., 116, F03009 (doi: 10.1029/2010JF001905)

Moholdt G and Kääb A (2012) A new DEM of the Austfonna ice cap by combining differential SAR interferometry with ICES at laser altimetry. Polar Res., 31, 18460 (doi: dx.doi.org/10.3402/polar. v31i0.18460)

Moholdt G, Hagen JO, Eiken T and Schuler T (2010) Geometric changes and mass balance of the Austfonna ice cap, Svalbard. Cryosphere, 4, 21-34 (doi: 10.5194/tc-4-21-2010)

Moore J, Grinsted A, Zwinger T and Jevrejeva S (2013) Semiempirical and process-based global sea level projections. Rev. Geophys., 51 (doi: 8755-1209/13/10.1002/rog.20015)

Morlighem M and 5 others (2010) Spatial patterns of basal drag inferred using control methods from a full-Stokes and simpler models for Pine Island Glacier, West Antarctica. Geophys. Res. Lett., 37 (doi: 10.1029/2010GL043853)
Nick F, Vieli A, Howat I and Joughin I (2009) Large-scale changes in Greenland outlet glacier dynamics triggered at the terminus. Nat. Geosci., 2, 110-114 (doi: 10.1038/NGEO394)

Nye JF (1970) Glacier sliding without cavitation in a linear viscous approximation. Proc. R. Soc. London A., 315, 381-403

Pattyn F (2003) A new three-dimensional higher-order thermomechanical ice sheet model: basic sensitivity, ice stream development, and ice flow across subglacial lakes. J. Geophys. Res., 108 (doi: 1 0.1029/2002JB002329)

Pattyn F and 20 others (2008) Benchmark experiments for higherorder and full-Stokes ice sheet models (ISMIP-HOM). Cryosphere, 2, 95-108 (doi: 10.5194/tc-2-95-2008)

Pattyn F and 27 others (2013) Grounding-line migration in plan-view marine ice-sheet models: results of the ice2sea MISMIP3d intercomparison. J. Glaciol., 59, 410-422 (doi: 10.3189/2013JoG12J129)

Phillips T, Rajaram H and Steffen K (2010) Cryo-hydrologic warming: a potential mechanism for rapid thermal response of ice sheets. Geophys. Res. Lett., 37, L20503 (doi: 10.1029/2010GL044397)

Phillips T, Rajaram H, Colgan W, Steffen K and Abdalati W (2013) Evaluation of cryo-hydrologic warming as an explanation for increased ice velocities in the wet snow zone and Sermeq Avannarleq and West Greenland. J. Geophys. Res.: Earth., 118, 1241-1256 (doi: 10.1002/jgrf.20079)

Pinglot J, Hagen JO, Melvold K, Eiken T and Vingent C (2001) A mean net accumulation pattern derived from radioactive layers and radar soundings on Austfonna, Nordaustlandet, Svalbard. J. Glaciol., 47, 555-566 (doi: 10.3189/172756501781831800)

Rae J and 14 others (2012) Greenland ice sheet surface mass balance: evaluating simulations and making projections with regional climate models. Cryosphere, 6, 1275-1294 (doi: 10.5194/tc-6-1275-2012)

Schäfer M and 6 others (2014) Assessment of heat sources on the control of fast flow of Vestfonna ice cap, Svalbard. Cryosphere, 8, 1951-1973 (doi: 10.5194/tc-8-1951-2014)

Schäfer M, Möller M, Zwinger T and Moore J (2015) Dynamic modelling of future glacier changes: mass balance/elevation feedback in projections for the Vestfonna ice cap, Nordaustlandet, Svalbard. J. Glaciol., 61, 1121-1136 (doi: 10.3189/ 2015JoG14J184)

Schoof C (2007) Ice sheet grounding line dynamics: steady states, stability and hysteresis. J. Geophys. Res. Earth Surf., 112 (doi: 10.1029/2006JF000664)

Schoof C and Hindmarsh R (2010) Thin-film flows with wall slip: an asymptotic analysis of higher order Glacier flow models. Q. J. Mech. Appl. Math., 63, 73-114 (doi: 10.1093/qjmam/hbp025)

Schuler T and 5 others (2007) Calibrating a surface mass balance model for the Austfonna ice cap, Svalbard. Ann. Glaciol., 46, 241-248 (doi: 10.3189/172756407782871783)

Schuler T, Dunse T, Østby T and Hagen JO (2014) Meteorological conditions on an Arctic ice cap - 8 years of automatic weather station data from Austfonna, Svalbard. Int. J. Climatol., 34, 2047-2058 (doi: 10.1002/joc.3821)

Schytt V (1964) Scientific results of the Swedish Glaciological Expedition to Nordaustlandet, Spitsbergen, 1957 and 1958. Geogr. Ann., 46, 243-281 (doi: 10.2307/520382)

Shepard D (1968) A two-dimensional interpolation function for irregularly-spaced data, In Proceedings 1968 23rd ACM National Conference, ACM, New York 517-524. (doi: 10.1145/800186.81061)

Taurisano A and 6 others (2007) The distribution of snow accumulation across the Austfonna ice cap, Svalbard: direct measurements and modelling. Poler Res., 26, 7-13 (doi: 10.1111/j.17518369.2007.00004.x)

Tulaczyk SM, Kamb B and Engelhardt HF (2000) Basal mechanics of Ice Stream B, West Antarctica. II. Undrained-plastic bed model. J. Geophys. Res., 105(B1), 483-494

Vasilenko E, Navarro F, Dunse T, Eiken T and Hagen J (2010) New low-frequency radio-echo soundings of Austfonna ice cap, Svalbard. In Ahlstrøm A and Sharp M, eds. The Dynamics and Mass Budget of Arctic Glaciers. Extended abstracts. Work-shop 
and GLACIODYN (IPY) meeting, 16-19 February 2009, Dan. Grønl. Geol. Unders. Rapp., 127. IASC Working Group on Arctic Glaciology, GEUS, Copenhagen

Weertman J (1957) On the sliding of glaciers. J. Glaciol., 3, 33-38

Zagorodnov VS, Sin'kevich SA and Arkhipov SM (1990) Gidrotermicheskiy rezhim ledorazdel'noy oblasti Vostochnogo ledyanogo polya, o. Severo-Vostochnaya Zemlya [Hydrothermal regime of the ice-divide area of Austfonna, Nordaustlandet]. Mater. Glyatsiol. Issled., 68, 133-141

Zagorodnov VS, Nagornov O and Thompson LG (2006) Influence of air temperature on a glacier's active-layer temperature. Ann. Glaciol., 43, 285-287

MS received 16 February 2016 and accepted in revised form 11 October 2016; first published online 20 December 2016 